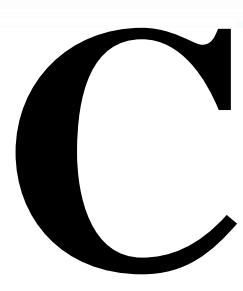

\title{
OMPLEMENTARITY AS A DRIVER OF VALUE IN BUSINESS INTELLIGENCE AND ANALYTICS ADOPTION PROCESSES
}

\author{
${ }^{1}$ Valter Moreno \\ ${ }^{2}$ Felipe Elias Lobo Vieira da Silva \\ ${ }^{3}$ Rodrigo Ferreira \\ ${ }^{4}$ Fernando Filardi
}

Objective: Investments in Business Intelligence and Analytics (BI\&A) are increasingly essential to a firm's competitiveness. Drawing on the Resource-Based View (RBV), our objective is to analyze the implementation of a BI\&A system at the Brazilian National Bank of Economic and Social Development (BNDES) to assess the generation of business value for the organization.

Methodology: We collected qualitative data through interviews, participant observation, and internal documents and communications. For data analysis, we followed the general coding, aggregation and synthesis process with the use of the qualitative data analysis software Atlas.ti.

Originality: Traditional Information Technology (IT) investment evaluation frameworks, especially on BI\&A systems, neglect the dynamic nature and the mutual influences of Information Systems assets and capabilities. Also, these frameworks lack studies on complementary socio-organizational capabilities in the business value generation process. Furthermore, RBV has rarely been employed in the study of the impact of BI\&A in organizations.

Main results: Our results revealed the critical role played by IT and organizational resources and capacities in the BI\&A adoption process, as well as the importance of the dynamics of complementarity and its positive outcomes in business.

Theoretical contribution: In our research, we provide evidence of RBV's potential to elucidate the complexities regarding the generation of sustainable business value, and therefore to explain the distinct results obtained by organizations that adopt BI\&A technologies.

Keywords: Business Intelligence. Information Technology Management. Resource-Based View. IT Value. Complementary Resources.

\section{Cite it like this:}

Moreno, V., Silva, F., Ferreira, R., \& Filardi, F. (2019). Complementarity as a Driver of Value in Business Intelligence and Analytics Adoption Processes. Revista Iberoamericana de Estratégia, 18(1). 57-70. https://doi.org/10.5585/ijsm.v18i1.2678

\footnotetext{
${ }^{1}$ Brazilian Institute of Capital Markets - IBMEC, São Paulo, Brazil. E-mail: valter.moreno@eng.uerj.br Orcid id: https://orcid.org/0000-0002-1782-2401

${ }^{2}$ Brazilian Institute of Capital Markets - IBMEC, São Paulo, Brazil. E-mail: felipe1911@ hotmail.com

${ }^{3}$ Brazilian Institute of Capital Markets - IBMEC, São Paulo, Brazil. E-mail: rodrigoferreira.adm@bol.com.br Orcid id: https://orcid.org/0000-0002-1766-0094
}

${ }^{4}$ Brazilian Institute of Capital Markets - IBMEC, São Paulo, Brazil. E-mail: fernando.filardi@ibmec.edu.br Orcid id: https://orcid.org/0000-0002-9333-0871 


\section{COMPLEMENTARIDADE COMO UM GERADOR DE VALOR EM PROCESSOS DE ADOPÇÃO DE BUSINESS INTELLIGENCE \& ANALYTICS}

Objetivo: Os investimentos em Business Intelligence and Analytics (BI\&A) são cada vez mais essenciais para a competitividade das empresas. Apoiado na Visão Baseada em Recursos (VBR), este estudo analisou a implementação de um sistema de BI\&A no Banco Nacional de Desenvolvimento Econômico e Social (BNDES) para avaliar a geração de valor para a organização.

Método: Coletamos dados qualitativos por meio de entrevistas, observação participante e em documentos internos e comunicações. A análise dos dados seguiu o processo usual de codificação, agregação e síntese, com auxílio do Atlas.ti, um software de análise de dados qualitativos.

Originalidade: As abordagens tradicionais de avaliação de investimentos em Tecnologia da Informação (TI), especialmente no caso de sistemas de BI\&A, negligenciam a natureza dinâmica e as influências mútuas dos ativos e capacidades de TI e as capacidades sócio-organizacionais complementares, no processo de geração de valor para o negócio. Além disso, a Visão Baseada em Recursos tem sido pouco empregada no estudo do impacto de sistemas de BI\&A nas organizações.

Resultados: Os resultados do estudo revelaram o papel fundamental desempenhado pelos recursos e capacidades organizacionais e de TI no processo de adoção de BI\&A, bem como a importância da dinâmica de complementaridade e seus resultados positivos.

Contribuições teóricas: Nesta pesquisa, fornecemos evidências do potencial da VBR para elucidar as complexidades envolvidas no uso da TI para a geração de valor para o negócio sustentável, e, portanto, para explicar os diferentes resultados obtidos por organizações que adotam sistemas de BI\&A.

Palavras-chave: Business Intelligence. Gestão de Tecnologia da Informação. Visão Baseada em Recursos. Valor de TI. Recursos Complementares.

\section{COMPLEMENTARIEDAD COMO UN GENERADOR DE VALOR EN PROCESOS DE ADOPCIÓN DE NEGOCIOS INTELLIGENCE \& ANALYTICS}

Objetivo: Las inversiones en Business Intelligence and Analytics (BI\&A) son cada vez más esenciales para la competitividad de las empresas. Apoyado en la Visión Basada en Recursos (VBR), este estudio analizó la implementación de un sistema de BI \& A en el Banco Nacional de Desarrollo Económico y Social (BNDES) para evaluar la generación de valor para la organización.

Método: Datos cualitativos fueron recolectados por medio de entrevistas, observación participante y en documentos internos y comunicaciones. El análisis de los datos siguió el proceso usual de codificación, agregación y síntesis, con ayuda del Atlas.ti, un software de análisis de datos cualitativos.

Originalidad: Los enfoques tradicionales de evaluación de inversiones en tecnología de la información (TI), especialmente en el caso de sistemas de BI\&A, descuidan la naturaleza dinámica y las influencias mutuas de los activos y las capacidades de TI y las capacidades socio-organizacionales complementarias, en el proceso de generación de valor para el negocio. Además, la Visión Basada en Recursos ha sido poco empleada en el estudio del impacto de sistemas de BI\&A en las organizaciones.

Resultados: Los resultados del estudio revelaron el papel fundamental desempeñado por los recursos y capacidades organizativas y de TI en el proceso de adopción de BI\&A, así como la importancia de la dinámica de complementariedad y sus resultados positivos.

Contribuciones teóricas: La investigación proporciona evidencia del potencial de VBR para dilucidar las complejidades involucradas en el uso de TI para la generación de valor para el negocio sostenible, y por lo tanto para explicar los diferentes resultados obtenidos por organizaciones que adopta sistemas de BI\&A.

Palabras clave: Business Intelligence. Gestión de Tecnología de la Información. Visión basada en recursos. Valor de TI. Recursos complementarios. 


\section{Introduction}

Despite the increasing investments in Information Technology (IT) and the significant number of scholarly studies on the creation of value with information systems (IS), cases of organizations that do not fully obtain the expected benefits when implementing a new system are still frequently reported (Arvidsson, Holmström \& Lyytinen, 2014; Hughes, Dwivedi, Simintiras \& Rana, 2016). Although IT investments are frequently perceived as essential drivers of business value, they do not guarantee the achievement of competitive advantage. It is how IT resources are used by companies that determine their ability to generate business value (Melville, Kraemer \& Gurbaxani, 2004; Nevo \& Wade, 2010; Schryen, 2013).

In the recent years, Business Intelligence and Analytics (BI\&A) has received considerable attention in the managerial and scholarly literature. BI\&A can be understood as a set of tools, technologies, applications, and processes for gathering, storing, accessing, and analyzing data to generate useful business information and help users make better decisions (Kakhki \& Palvia, 2016; Namvar, Cybulski \& Perera, 2016; Wixom \& Watson, 2010).

According to a recent industry report, the BI\&A market is forecast to reach $\$ 22.8$ billion by 2020 (Gartner, 2017). Organizations perceive BI and analytics technologies as means to better understand and quickly adapt to changes in their microenvironment and customer needs, and thereby, to become more competitive and enhance their performance (cf. Park, El Sawy, \& Fiss, 2017; Torres, Sidorova, \& Jones, 2018). However, although investments in those technologies continue to increase, it is still difficult to measure their return due to the lack of appropriate methods and consensual success criteria (Popovič, Turk \& Jaklič, 2010; Yeoh \& Popovič, 2016).

One of the significant challenges for companies that decide to implement BI\&A systems is to gather stakeholders' support to identify and make available the necessary resources and promote internal adjustments so that the new technology assets can be used effectively over time to enhance organizational performance continuously (Hughes, Dwivedi, Simintiras \& Rana, 2016; Yeoh \& Popovič, 2016).

This study addresses the overarching issue of the generation of business value with IT by focusing on the specific problem of evaluating the contribution of
BI\&A systems to organizations. Many of the benefits of BI\&A technologies are intangible, which makes the related investments difficult to evaluate with traditional project assessment approaches (Dobrev \& Hart, 2015). Moreover, IT traditional investment evaluation frameworks (cf. Olszak, 2016; Park, El Sawy, \& Fiss, 2017) usually neglect the dynamic nature and the mutual influences of Information Systems (IS) assets and capabilities and the complementary socio-organizational capabilities in the business value generation process (Schryen, 2013).

To shed light on the intricate mechanisms of business value generation as they unfold over time, we investigated the adoption of BI\&A systems by the Brazilian National Bank for Economic and Social Development (BNDES). In our study, we identified and analyzed the barriers and workarounds that emerged during the adoption process, as well as IT and organizational resources and capabilities that were essential to the generation of value to the organization.

We employed the Resource-Based View (RBV) as our theoretical lenses (Barney, 1991, 2001; Wade \& Hulland, 2004), which attribute the success of the value generation process to the development of adequate, complementary resources and capacities (Melville, Kraemer, \& Gurbaxani, 2004; Nevo \& Wade, 2011, 2010). To our best knowledge, RBV has rarely been employed in the study of the impact of BI\&A in organizations (Fink, Yogev, \& Even, 2017; Olszak, 2016; Sangari \& Razmi, 2015). Our research provides evidence of its potential to elucidate the complexities involved in the generation of business value over time, and therefore to explain the distinct results obtained by organizations that adopt Business Intelligence technologies.

The paper is structured as follows: Section 2 presents the essential concepts of the ResourceBased View, the generation of value with IT, and Business Intelligence; Section 3 presents the methodological procedures used in the study; Section 4 describes the BI\&A adoption process at BNDES; Section 5 identifies and analyzes the related IT and organizational resources and capacities, their dynamic, complementary interactions throughout the project, and the enhanced capabilities developed by the organization; lastly, Section 6 presents our considerations regarding the contributions of the study and the challenges related to understanding the generation of business value with IT, and BI\&A systems in particular, in organizations. 


\section{Conceptual Background}

This section presents the essential concepts that constitute the theoretical lenses adopted in the study. First, the Resource-Based View (RBV) theory is introduced. Next, we briefly review Melville et al.'s (2004) integrative model of the generation of business value with IT and Nevo and Wade's (2011, 2010) view on resource complementarity and value generation. Both approaches are based on the RBV. Finally, we present the fundamental concepts of Business Intelligence and Analytics, as well as recent studies on the benefits of BI systems.

\section{The Resource-Based View (RBV)}

The Resource-Based View (RBV) proposes that the source of competitive advantage lies primarily in the resources and capacities developed and controlled by the firm, and secondarily in the structure of its industry (Barney, 1991; Rivard, Raymond \& Verreault, 2006).

Organizational resources can be defined as "tangible or intangible factors of production that organizations own, control, or have access to on a semi-permanent basis" (Nevo \& Wade, 2010), while a capacity would be "a high-level routine (or collection of routines) that, together with its implementing input flows, confers upon an organization's management a set of decision options for producing significant outputs of a particular type" (Winter, 2003). RBV proposes that firms achieve superior performance by developing and controlling rare, valued, hard-to-imitate resources and capacities, for which competitors cannot create substitutes (Barney, 2001).

Since the 1990's, various studies have been conducted to increase our understating of topics such as how resources and capacities are employed and combined in companies; which of them can generate business value and sustainable competitive advantage, and in which conditions; and what the origins of business heterogeneity are (Crook, Ketchen, Combs \& Todd, 2008; Ray, Barney \& Muhanna, 2004; Schmidt \& Keil, 2013).

In the Information Systems field, authors such as Mata, Fuerst \& Barney (1995), Wade and Hulland (2004) and Rivard, Raymond and Verreault (2006) have explored the implications of RBV for competitiveness and organizational performance with a focus on IT-related resources and capacities.

\begin{tabular}{ll}
\hline \multicolumn{1}{c}{ IT Resource and Capacity Type } & \multicolumn{1}{c}{ IT Resources and Capacities } \\
\hline Outside-in & External relationship management \\
\cline { 2 - 2 } & Market responsiveness \\
\hline Inside-out & IS infrastructure \\
\cline { 2 - 2 } & IS technical skills \\
\cline { 2 - 2 } & IS development \\
\cline { 2 - 2 } Spanning & Cost efficient IS operations \\
\cline { 2 - 2 } & IS-business partnerships \\
\cline { 2 - 2 } & IS management/planning \\
\hline
\end{tabular}

Table 1: IS Resources and Capacities

Source: Wade \& Hulland (2004).

In their seminal study, Wade and Hulland (2004) identified eight essential information systems resources and capacities, which they classified into three categories: outside-in, inside-out, and spanning (Table 1). Outside-in resources and capacities aim at anticipating market requirements, such as external relationship management and market responsiveness. The inside-out resources and capacities are IS infrastructure, IS technical skills, IS development, and cost-efficient IS operations. They are used by the firm to respond to external demands and opportunities. The spanning resources and capacities, IS-business partnerships and IS management and planning, pertain to the integration of the firm's IT area with other business areas. Based on their analysis of the attributes of these resources and capacities, the authors suggest that resources and capacities of the outside-in and spanning categories tend to have a stronger impact on a firm's initial and 
long-term competitive position than those of the inside-out category.

\section{Business Value of Information Technology}

Despite the various studies conducted in the last decades, the investigation of how IT investments can lead to increased business value remain relevant, as findings are still inconsistent and technology is continuously evolving (Sabherwal \& Jeyaraj, 2015). Over time, RBV has asserted itself as one of the leading theories adopted by researchers in their efforts to better understand the generation of business value with IT (Nevo \& Wade, 2010; Schryen, 2013). In the present study, we use two complementary models developed by Melville, Kraemer \& Gurbaxani (2004) and Nevo \& Wade (2010) - both of which based on RBV - to look into the issue of how a firm's investments in a BI\&A system can be translated into business value.
In their model (Fig. 1), Melville, Kraemer \& Gurbaxani (2004) consider two basic types of resources: (1) IT resources, which are classified into technological (IRR) and human (HIR); and (2) complementary organizational resources. Following previous empirical and conceptual developments,

Melville et al. suggest that IT resources can lead to increased business value and organizational performance only when they are complemented with adequate organizational resources. Furthermore, it is through their positive impact on business processes and their performance that such complementary resources would create additional business value and result in better firm performance. In this way, ensuring the complementarity between IT and organizational resources and capacities should be understood as a requirement for the generation of business value with IT investments.

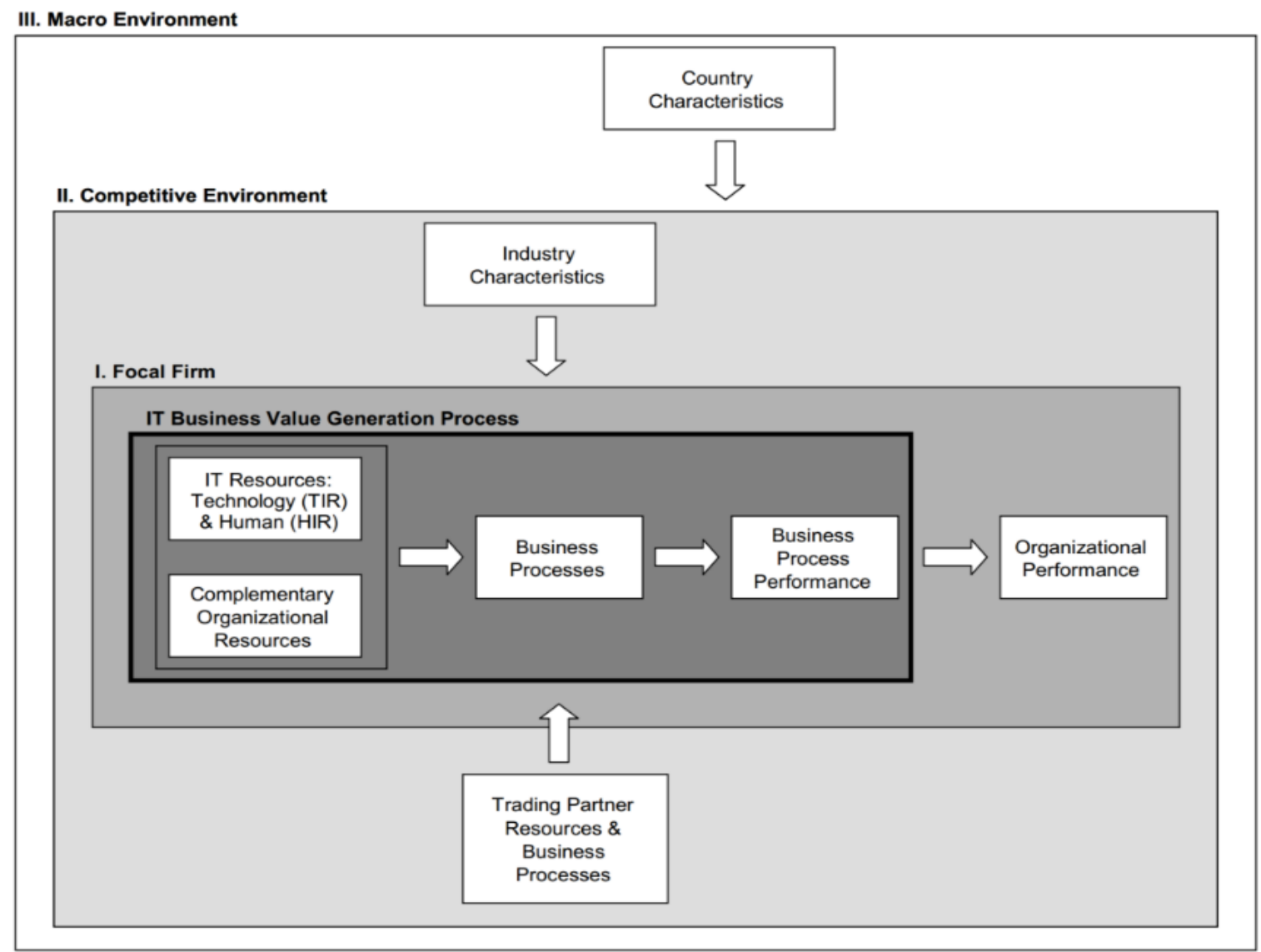

Figure 1: Melville et al.'s Integrative Model of the Business Value of IT Source: Melville et al. (2004, p. 293).

Melville, Kraemer \& Gurbaxani (2004) model also highlights the contingent nature of the value generation process. In those authors' view, actual business value delivered to the organization varies with the characteristics of the country and industry in which the firm operates and the resources and processes of trading partners upon which it depends. Relevant country characteristics include the level of 
development, economic growth, education, local culture, and the available IT and communications infrastructure. Industry characteristics include the intensity of rivalry among competitors, and industry laws, regulations, and incentives.

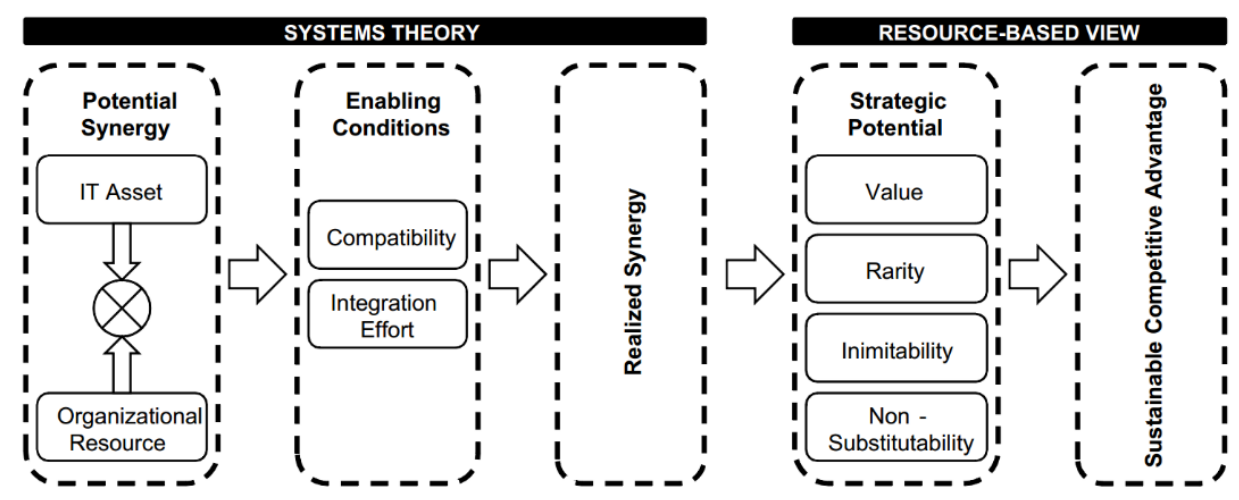

Figure 2: Potential and Realized Synergy of IT and Organizational Resources Source: Nevo \& Wade (2010, p. 171).

Nevo and Wade's (2010) model (Fig. 2) focuses on the development of new resources and capacities that potentially generate sustainable competitive advantage. The authors emphasize the importance of IT and organizational resources and capacities being compatible and integrated with each other for the realization of synergy by the firm. Whenever necessary, the organization should take the necessary steps to increase their level of compatibility and integration, that is, to ensure complementarity, as "the extent of synergy borne out of a relationship between an IT asset and an organizational resource can determine the ensuing IT-enabled resource's strategic potential" (Nevo \& Wade, 2011). Such potential can then be realized as operational benefits (increase ed efficiency and reduced operational costs) and strategic benefits (increased external effectiveness and competitive advantage), depending on the value, rarity, imitability, and nonsubstitutability of the synergic resources and capacities developed by the firm (Nevo \& Wade, 2010; Schryen, 2013).

\section{Business Intelligence and Analytics (BI\&A)}

BI\&A technology has its origins in the decision support systems (DSS) developed in the 1960s and 70 s, when researchers discussed the importance of using IT to integrate internal and external information and improve decision making in organizations (Negash, 2004; Watson, 2009; Wixom, Yen \& Relich, 2013). The term "Business Intelligence and Analytics" involves all the resources and capacities required to transform data into intelligence that the organization can use effectively in its decision-making processes (Miller, Bräutigam \& Gerlach, 2006; Wixom, Yen, \& Relich, 2013). Nowadays, BI\&A technology is seen as a source of competitive advantage (Côrte-Real, Oliveira \& Ruivo, 2017), as it allows companies to access and use vast amounts of complex, volatile data to generate and deliver the right information to the right person, at the right time (Chen, Chiang \& Storey, 2012).

Popovič, Turk \& Jaklič (2010) proposed a conceptual model for evaluating the contribution of BI\&A systems to organizational performance (Fig. 3). The effects on business performance depend on how information delivered by the systems is used in the business processes to improve decision making. This, in its turn, depends on the quality of this information (comprehensiveness, accuracy, clarity, conciseness, consistency, correctness, currency, convenience, timeliness, traceability, and interactivity), which is a result of the maturity of the BI\&A systems of the organization (available data sources, level of data integration, analytics tools used for decision making purposes). The degree to which an organization can effectively use information in its business processes depends on various factors, defined by Popovič, Turk \& Jaklič (2010) as BIS absorbability. They include strategy alignment, a culture of continuous process improvement, a culture of information use and analysis, decision process management, cooperation between IT, and business and technological readiness. 


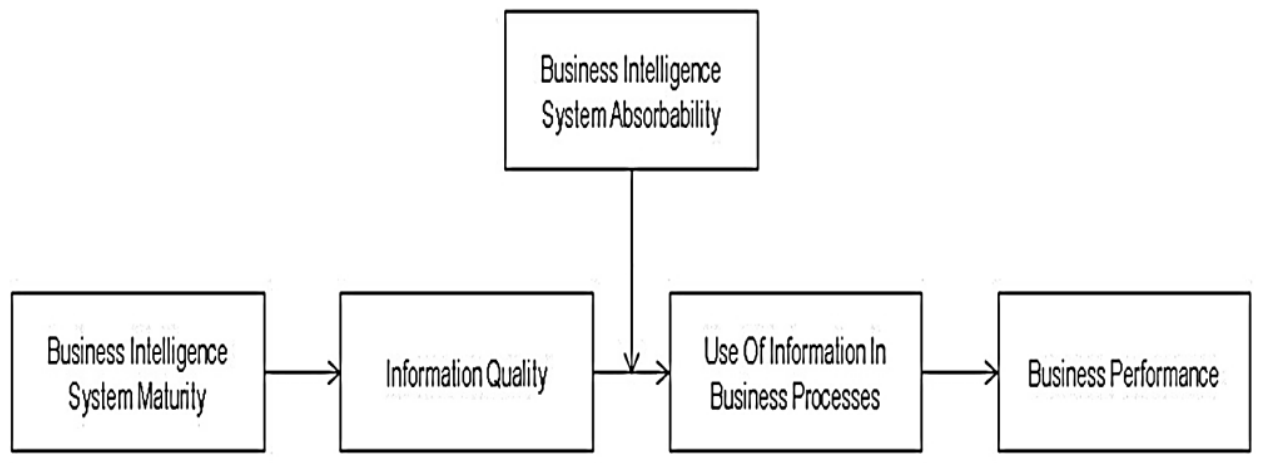

Figure 3: The Business Value of BI\&A systems

Source: Popovič, Turk \& Jaklič, 2010.

Recent empirical results indicate that the effective adoption and usage of BI\&A technologies can help organizations better understand their customers and their macroenvironment, improve absorptive capacity, decision making, business processes and agility, and generate valuable insights from the available data (Chae, Olson, \& Sheu, 2014; Dobrev \& Hart, 2015; Fink et al., 2017; Olszak, 2016; Sangari \& Razmi, 2015; Seddon, Constantinidis, Tamm, \& Dod, 2017; Shen et al., 2015; Wang \& Byrd, 2017). Nevertheless, in some organizations, the strategic potential of BI\&A solutions is still poorly understood by management, which leads to the underutilization of the technology as a mere operational decision support tool and an ad hoc report generator (Olszak, 2016; Vidgen, Shaw, \& Grant, 2017).

\section{Research Method}

To achieve the previously defined objectives, we conducted an exploratory case study on the implementation process and subsequent usage of a BI\&A system at the Brazilian National Bank for Economic and Social Development (BNDES). The case study research method is especially useful in situations in which the researcher has little control over the events or phenomena of interest, and the boundaries between the latter and the context in which they occur are not clearly defined (Yin, 2013).

The Brazilian National Bank for Economic and Social Development (BNDES) is a public company linked to the Ministry of Planning, Development, and Management. It is considered the main instrument for implementing the investment policy of the Brazilian Federal Government. Its primary objective is to support programs and projects and to provide services that contribute to the economic and social development of the country in the long term. The reasons for conducting the research at BNDES were threefold: (1) the organization had been investing in BI and Analytics solutions since the early 2000's, which allowed us to investigate a long-term adoption process, with its barriers, workarounds, and results as they unfolded over time; (2) although BNDES is a public company, it has performance and efficiency goals similar to those usually defined by private companies, which makes our results potentially applicable to a broader context; and (3) we were granted full access to employees and documentation related to the adoption of BI\&A at the bank.

Multiple sources of data were considered in the study:

(1) Primary data: We gathered rich qualitative data obtained in in-depth interviews conducted between June and September 2013, with 12 managers, two coordinators, and two business analysts from the bank, who were members of the BI\&A implementation team. These participants were selected so that we could obtain the perspectives of different stakeholders on the development of the project and the subsequent usage of the system in the organization. The interview protocol included general open questions about the significant events in the adoption process, barriers faced over time and their solutions, success factors, and outcomes. All interviews were recorded and transcribed. Also, participant observation was conducted by one of the researchers who worked for BNDES. He attended several meetings related to the BI\&A project and had frequent interactions with both team members and end users. His detailed field notes were incorporated into the data analyzed in the study.

(2) Secondary data: We had access to internal documents of BNDES, such as the acquisition contracts related to the BI\&A system, information from the HR area about the training offered to users, and the conceptual information model prepared with the support of a consulting company, which was the basis for the implementation of the system. 
Furthermore, we were granted access to the results of an internal survey conducted in 2012 and 2013, on the benefits, problems and suggested improvements related to the BI\&A project. The data was collected via an electronic questionnaire, which was composed of closed and open questions. The questionnaire was answered by a sample of 100 BI\&A users from 22 areas of the bank.

(3)

Data analysis followed the general coding, aggregation and synthesis procedure described by Friese (2014). Following the theoretical lens adopted in our study, we strove to identify in the analysis process the resources and capacities that contributed to the generation of business value for BNDES. The secondary data were used to complement and ratify the conclusions derived from the analysis of the primary data, constituting, therefore, a mechanism of triangulation in the study.

\section{The Adoption of BI\&A Technology by BNDES}

Since the late 1990's, BNDES had been already assessing the potential benefits of the adoption of a Business Intelligence and Analytics system. Early in the 2000's, the bank conducted a selection process to define the BI\&A solution it would adopt. The following criteria were considered: functionality, ease of use, graph and report formatting, compatibility with Microsoft Office, the structuring of information, and security. It was then decided to acquire licenses of Business Objects (BO), one of the leading BI\&A software solutions at that time.

In the early 2000's, the primary corporate information systems of BNDES still ran in a mainframe environment. The tools for extracting information were difficult to use and required advanced technical knowledge. Also, reports already had a predefined format, not allowing users to dynamically access data and perform ad-hoc analyses to support their decision-making process. Such a scenario made business users extremely dependent on IT professionals.

Because BI\&A technology was new in the market and BNDES at that time, some barriers were faced by the organization at the beginning of the project. In especial, it was hard to obtain the sponsorship of the business areas, which were reluctant to become involved in the implementation effort. Neither top management nor the primary stakeholders of the project were engaged and committed to its success. According to a manager interviewed in the study: "to [top management] what mattered the most was gaining information, not the manner in which it was obtained."
Despite the lack of support, the implementation of the BI\&A system continued to take place. In retrospect, it seems to have gone through different phases. The first one involved prospecting the technological solution and the execution of a pilot project. It was considered critical for the whole deployment initiative, as it included the initial efforts to seek support from the primary users and the development of workarounds for significant technical challenges. Technology and specialized services were procured to prepare the teams involved in the impending changes. In the opinion of one of the managers, "barriers were overcome - and the results showed -with much talking, patience, communication, always remaining close to the user, so that nothing hindered the generation of information."

In 2002, with the implementation of essential BI\&A components and the development of the related technological infrastructure, a second phase started, with the project gaining visibility across BNDES. During this stage, and until 2006, the project team developed several Business Object universes, which are semantic layers that reside between an organization's databases and the end users. Universes allow business users to understand and interact with the data in a way that makes sense to them, without having to know the technical details of the database and storage systems that compose the BI\&A infrastructure. This allowed for significant growth of interest in the BI\&A project. Over time, different areas of the bank started to use the solutions more intensively in their day-to-day activities.

In the third phase of the project, from 2007 to 2009 , the scope of managerial information made available to business users was expanded. Eleven new universes were created for specific business arenas. Also, different profiles of BI\&A users were identified, such as those that merely read the reports generated with the system, and those that had the expertise and interest in creating the reports. This mapping helped the BI\&A teams understand the users' needs and abilities and better allocate their scarce resources to help the users themselves fulfill their business needs. According to one the managers: "the transactional system development team did not have the resources to create the reports requested by the business users, and, if they had to queue up the work for the ETL team, it would take a long time, because that team was overloaded... [However,] despite being fast to create, the universe needs a lot of care to be properly used; one needs to know how to navigate, and it can trick even more experienced 
users." The fourth phase of the adoption of the BI\&A technology by BNDES started in 2010 and was focused on establishing a governance system for Business Intelligence and Analytics usage and future development at the bank. Several actions were taken for this purpose, including the creation of a business area responsible for BI\&A governance; the formalization of the support of the Change Management area to guide and manage all communications related to the BI\&A project; the definition of the roles and responsibilities of the primary stakeholders in the IT and business areas; and the definition of rules, policies, and information standards to be used in future developments.

When data collection for this study took place, in 2013 and 2014, BNDES was preparing to invest in new BI\&A technologies, as the scope and level of sophistication of end users' needs continued to grow. By that time, the benefits of the Business Intelligence and Analytics efforts were widely recognized. An internal survey with users from 22 business areas revealed that the following points were perceived as significant contributions of the adoption of BI\&A by the bank: (1) better capacity to fulfill compliance requirements and the needs of the Brazilian society; (2) increased productivity and analysis capability; (3) better access to, and communication of managerial information; (4) increased capacity to answer critical business questions; (5) better monitoring of business performance and strategic indicators; (6) increased capacity to identify business opportunities; and (7) reduced costs and improved financial performance.

The Dynamics of Complementarity and Its Outcomes

\section{IT Resources and Capacities in the BI\&A Project}

We identified in our analysis the eight IT resources and capacities defined by Wade and Hulland (2004). Although some were not as fully developed as others at the beginning of the project, all of them seemed to have been subsequently strengthened as the BI\&A implementation unfolded at BNDES. They are described below:

- Market responsiveness: early in the 1990's, the IT area had already realized the need to invest in a new technology that would enable BNDES to better manage and take advantage of the information it gathered. It was able to identify and investigate the potential benefits, costs, and risks of BI\&A solutions at a time when the technology was still incipient. The IT area continued to monitor the market and assess technological alternatives as far as their capacity to deliver business value throughout the four phases of the project. Over time, new Business Intelligence and
Analytics products were integrated into the bank's systems.

- Management of external relationships: since the beginning of the BI\&A project, the IT area had to engage with technical service providers, such as software vendors and software maintenance companies, and specialized consulting companies. These relationships were instrumental in the development of internal expertise on Business Intelligence, through formal training and informal knowledge sharing with the project team over the duration of the BI\&A initiative.

- IS-business partnerships: the initial positive results obtained with the new BI\&A technology increased the visibility of the project in the organization and led to the establishment of a partnership between the business areas and the IT area. To a great extent, this was possible because of the active communication and relationship development skills of the project team. The continuous attention paid by the team to business areas' needs strengthened this partnership over time.

- IS planning and change management: this capacity was more evident in the fourth phase of the project, with the development of the BI\&A governance structure. This was the first time IT and business invested time and resources to create a Business Intelligence and Analytics long-term vision and the necessary processes and structures to help the organization achieve its related objectives.

- IS infrastructure: BNDES built a robust technological infrastructure to fully support the BI\&A system. This infrastructure continued to be improved upon as the project progressed. For instance, the bank acquired software licenses of Business Objects and other related SAP modules, continuously developed its ETL (Extract, Transform, Load) systems, and invested in servers, storage and networking products required to run those systems.

- IS technical skills: the IT team was able to put in place a sophisticated BI\&A system and infrastructure to meet the demands of the business areas over time. This required not only the development of expertise in Business Intelligence, but also in software development, hardware and networking, database management, and systems integration. Additional knowledge was sought externally and made available to the team through training, professional meetings and conference attendance, and informal contacts with vendors and consultants.

- IS development: the IT area created a technological and organizational environment that allowed it to experiment with new BI\&A technologies and assess the possibility of generating additional business value with products that were just offered in the market. They continued to develop and 
improve the BI\&A system as the needs of the business areas increased in scope and complexity.

- Cost effective IS operations: over time, the IT area could deliver new BI\&A services more efficiently to the end users. As the user base increased throughout the bank, operating costs remained relatively fixed. For instance, the development of BO universes helped the organization reduce the development, implementation and maintenance costs related to ETL processes.

\section{-}

Complementary Organizational Resources and Capacities

The generation of business value with investments in IT is contingent upon the availability of complementary organizational resources and capacities (Melville, Kraemer \& Gurbaxani, 2004; Nevo \& Wade, 2010; Schryen, 2013; Wade \& Hulland, 2004). The following complementary resources and capacities were identified in our analysis:

- Training: BNDES's Human Resources area acted upon the knowledge gaps identified by the BI\&A team to provide appropriate training to business users. Approximately 2,402 hours of BI\&A coursework were offered, covering topics such as the report generation with Business Objects, basic and advanced analysis with Business Objects and related BI\&A products, and Business Intelligence and Analytics best practices. HR worked together with IT to design and offer the courses internally, taking advantage of the expertise developed by the BI\&A team.

- Process orientation: BNDES implemented SAP in parallel with the BI\&A initiative. This required the identification, mapping, and redesign of business processes, which unveiled the information needs and available resources for the main areas of the bank.

- Organizational structure: during the BI\&A implementation, IT was centralized, and new multifunctional areas were created, whose responsibilities included the management of business information and BO universes, as well as related BI\&A systems. In the last phase of the project, new organizational structures were set up to manage all BI\&A resources within the IT area, and implement, control and further develop the new BI\&A governance mechanisms. Also, executive committees were established to follow the progress of the BI\&A initiative and its deliveries.

- Strategic focus on business integration: BNDES strategic objectives made explicit the need to integrate the whole organization to promote better management practices and decision making. The BI\&A initiative was included in the bank's strategic plan as a means to provide an integrated view of the business based on the information that flowed among its areas. This also highlights the commitment of top management to the project.

- Organizational culture: even before the beginning of the project, there was an institutional effort at BNDES to promote the integration of the organization and the standardization and sharing of information, as well as to emphasize the importance of making decisions based on the analysis of up-todate, consistent, reliable data. The strengthening of values and beliefs that were in line with the goals of the BI\&A effort helped employees embrace the new technology.

By themselves, the IT resources and capacities listed in section 5.1 would not be able to deliver the results that the company expected to achieve with the BI\&A effort. As implied in the description above, essential interactions between IT and organizational resources and capacities were identified in all phases of the project.

IT's market responsiveness was enabled by the support BNDES's top management, which was reinforced by the bank's focus on business integration and the abovementioned values and beliefs of the organizational culture. IT's capacity to establish productive external relationships, together with its technical and software development skills, allowed the bank to develop the necessary BI\&A infrastructure and expertise. The latter was embedded into business processes and activities through continuous training, business process management initiatives supported by new information systems and intensive cross-functional communication. In its turn, the constant interaction between different areas and the IT team, enhanced and supported by the creation of multifunctional organizational structures and governance mechanisms, led to the development of a strong business-IT partnership. Because of this, on the one hand, new technological solutions could be investigated and evaluated as far as their capacity to address business needs; on the other hand, business areas' demands could be adjusted in the face of the technological limitations and constraints that typically mark the implementation of new information systems. Especially from 2002 on, both business and IT worked together to fulfill BNDES's strategic vision and help the organization achieve its objectives with the support of BI\&A technology. The capacity to implement and continuously develop the systems in tandem with emerging business needs, as 
well as to run them in a cost-effective way, increased the value generated with the new technology to BNDES, thereby strengthening the commitment of the organization not only to the project, but also to its strategic vision and the information-related values and beliefs it had been promoting.

By the end of the data collection for this study, it was evident that IT and organizational capacities and resources still complemented and strengthened each other, in a self-sustaining growth cycle. The mutual adjustment and improvement of organizational practices and BI\&A technology created the necessary conditions for the continuous generation of business value.

This high degree of complementarity was expressed in the constant interaction, that was observed during and after the project, between (1) committed, trained human resources, (2) working in organizational structures integrated by optimized business processes (3) and supported by BI\&A resources that were adapted and adjusted whenever necessary, (4) in an environment infused with applied knowledge that was shared among internal areas and with external agents.

\section{Enhanced Resources and Capacities}

Our analysis revealed that, with the implantation of the BI\&A technology, new resources and capacities were developed by BNDES. As proposed by Nevo and Wade (2010), the complementarity of IT and organizational resources and capacities that mutually reinforced each other in a synergic cycle allowed the bank to enhance existing resources and capacities and develop new ones. This was only possible to the extent that BNDES invested in efforts to improve the compatibility and level of integration of IT and organizational assets, such as the design and delivery of extensive BI\&A training for end users, and the creation of multifunctional teams and governance mechanisms to address BI\&A issues and ensure the alignment between technology and organizational needs.

In general, the optimization of business processes, supported by integrated systems, a knowledgeable, committed workforce, and dedicated organizational structures, intensified and accelerated the flow of information among areas and with relevant external partners, and improved managerial practices and decision making in the organization. By the end of the study, BNDES had significantly enhanced its monitoring and analytical capacities and was able to identify and act upon business opportunities more quickly. For instance, the time necessary to analyze and provide information to top management, business areas, and external stakeholders was substantially reduced (e.g., the time required to evaluate collateral assets in loan operations decreased by $50 \%$ ). The bank was also able to pinpoint potential opportunities to increase the level of integration and flexibility of its business processes with the help of new information technologies, as well as to increase efficiency and operational agility.

\section{Conclusion}

Our study made evident the importance of the complementarity of IT and organizational resources and capabilities for the generation of business value with BI\&A technology. It contributes to the extant scholarly literature by: (1) providing empirical evidence of the IT resources and capacities defined by Wade and Hulland (2004); (2) identifying and describing critical organizational resources and capacities that worked together with the former to strengthen and further develop BNDES's competencies; (3) unveiling the mutually reinforcing cycle of complementarity that tied together IT and organizational resources and capacities; and (4) identifying how the realized synergies in the BI\&A initiative led to the continuous development of the monitoring, analytical and general decision making capacities of BNDES, thereby generating operational and strategic benefits, and thus, business value. In this way, the present study supports the models developed by Melville, Kraemer \& Gurbaxani (2004) and Nevo and Wade (2010) and ratifies the empirical findings of authors such as Nevo and Wade (2011).

Our results also highlight the importance of efforts to increase the compatibility and level of integration of BI\&A assets and vital organizational resources (Nevo \& Wade, 2010; Schryen, 2013). The results achieved by BNDES would not be possible if not for the offer of customized training that matched the different needs of the various groups of business users, and the development of additional organizational structures, business processes, policies, roles and norms to establish a BI\&A governance at the organization. These efforts increased the level of complementarity between related IT assets and organizational resources and capacities, acting as a catalyst for the already mentioned value generation cycle.

It is important to note that, insofar as the newly developed BI\&A resources and capabilities of BNDES are a result of the unique, complex experiences and events that marked the bank's journey, they tend to be not only valuable but also rare and hard to imitate and substitute. This resonates 
with fundamental premises of RBV: the heterogeneity of the resources and capacities controlled by firms in an industry, and the attributes they must have to be able to generate sustainable competitive advantage. As business needs change and become more sophisticated, and new BI\&A technologies are investigated and adopted by BNDES, such resources and capacities are prone to evolve, reinforcing their potential to generate business value and increase the bank's competitiveness.

The analysis of the BNDES case also provided support for Popovič, Turk \& Jaklič (2010) business value framework. Our findings are in line with the proposed mediation role played by information quality and business processes, as well the moderating role played BIS absorbability (strategy alignment, a culture of information use and analysis, cooperation between IT and business, and technological readiness) in the BI\&A value generation process.

From a managerial standpoint, the contributions of our study are also significant. First, it points out critical success factors in a large, complex BI\&A

\section{References}

Arvidsson, V., Holmström, J., \& Lyytinen, K. (2014). Information systems use as strategy practice: A multi-dimensional view of strategic information system implementation and use. The Journal of Strategic Information Systems, 23: 45-61.

Barney, J. B. (1991). Firm resources and sustained competitive advantage. Journal of Management, 17 (1), 99.

Barney, J. B. (2001). Resource-based theories of competitive advantage: A ten-year retrospective on the resource-based view. Journal of Management, 27 (6), 643-650.

Chae, B., Olson, D., \& Sheu, C. (2014). The impact of supply chain analytics on operational performance: a resource-based view. International Journal of Production Research, 52(16), 4695-4710.

Chen, H., Chiang, R. H. L., \& Storey, V. C. (2012). Business Intelligence and Analytics: From Big Data to Big Impact. MIS Quarterly, 36: 11651188. implementation. Such analysis may guide companies that face similar challenges in their investments and allocation of resources. Second, by describing the dynamics of the interplay between IT and organizational resources and capacities, it highlights the possibility of a company extracting increasing operational and strategic benefits from its BI\&A investments. In the case of BNDES, such additional gains seem to have required only incremental investments in the technology itself, being driven mostly by the continuous development of the monitoring, analysis, and decision-making capacities of the business users.

Given that only one BI\&A project was investigated in this study, we suggest that future research endeavors continue to collect evidence to assess the theoretical propositions of the literature on the business value of IT, and the results we obtained.

Companies operate in different macroenvironments and control distinct sets of resources and capacities. It is indeed worth investigating the extent to which theories and observed benefits are contingent on such factors.

Côrte-Real, N., Oliveira, T., \& Ruivo, P. (2017). Assessing business value of Big Data Analytics in European firms. Journal of Business Research, 70: 379-390.

Crook, T. R., Ketchen Jr, D. J., Combs, J. G., \& Todd, S. Y. (2008). Strategic resources and performance: a meta-analysis. Strategic Management Journal, 29: 1141-1154.

Dobrev, K., \& Hart, M. (2015). Benefits, Justification and Implementation Planning of RealTime Business Intelligence Systems. Electronic Journal of Information Systems Evaluation, 18(2), 104.

Fink, L., Yogev, N., \& Even, A. (2017). Business intelligence and organizational learning: An empirical investigation of value creation processes. Information \& Management, 54(1), 38-56. https://doi.org/10.1016/j.im.2016.03.009

Friese, S. (2014). Qualitative Data Analysis with ATLAS.ti (2nd ed.). Thousand Oaks, CA: Sage Publications.

Gartner. (2017, February 17). Analytics Trends to Be Explored at Gartner Data \& Analytics Summits 2017. Retrieved September 24, 2018, from 
https://www.gartner.com/en/newsroom/pressreleases/2017-02-17-gartner-says-worldwidebusiness-intelligence-and-analytics-market-toreach-18-billion-in-2017

Hughes, D. L., Dwivedi, Y. K., Simintiras, A. C., \& Rana, N. P. (2016). Project Failure and Its Contributing Factors. Success and Failure of IS/IT Projects: A State of the Art Analysis and Future Directions. New York: Springer International Publishing.

Kakhki, M. D., \& Palvia, P. (2016). Effect of Business Intelligence and Analytics on Business Performance. In Proceedings of the XXII Americas Conference on Information Systems (AMCIS) (pp. 1-10). San Diego: Association for Information Systems (AIS).

Mata, F. J., Fuerst, W. L., \& Barney, J. B. (1995). Information technology and sustained competitive advantage: a resource-based analysis. MIS Quarterly, 19: 487-505.

Melville, N., Kraemer, K., \& Gurbaxani, V. (2004). Information Technology and Organizational Performance: An Integrative Model of IT Business Value. MIS Quarterly, 28(2), 283-322.

Miller, G. J., Bräutigam, D., \& Gerlach, S. V. (2006). Business intelligence competency centers: a team approach to maximizing competitive advantage, 8. John Wiley \& Sons.

Namvar, M., Cybulski, J. L., \& Perera, L. (2016). Using business intelligence to support the process of organizational sensemaking. Communications of the Association for Information Systems, 38: 330-352.

Negash, S. (2004). Business Intelligence. Communications of the Associations for Information Systems, 13: 177-195.

Nevo, S., \& Wade, M. (2011). Firm-level benefits of IT-enabled resources: A conceptual extension and an empirical assessment. Journal of Strategic Information Systems, 20(4), 403-418.

Nevo, S., \& Wade, M. R. (2010). The Formation and Value of IT-enabled Resources: Antecedents and Consequences of Synergistic Relationships. MIS Quarterly, 34(1), 163-183.

Olszak, C. M. (2016). Toward Better Understanding and Use of Business Intelligence in Organizations. Information Systems Management, 33(2), 105-123.
Park, Y., El Sawy, O. A., \& Fiss, P. C. (2017). The Role of Business Intelligence and Communication Technologies in Organizational Agility: A Configurational Approach. Journal of the Association for Information Systems, 18(9).

Popovič, A., Turk, T., \& Jaklič, J. (2010). Conceptual Model of Business Value of Business Intelligence Systems. Management: Journal of Contemporary Management, 15(1), 5-29.

Ray, G., Barney, J. B., \& Muhanna, W. A. (2004). Capabilities, business processes, and competitive advantage: Choosing the dependent variable in empirical tests of the resource-based view. Strategic Management Journal, 25: 23-37.

Rivard, S., Raymond, L., \& Verreault, D. (2006). Resource-based view and competitive strategy: An integrated model of the contribution of information technology to firm performance. The Journal of Strategic Information Systems, 15: 29-50.

Sabherwal, R., \& Jeyaraj, A. (2015). Information Technology Impacts on Firm Performance: An Extension of Kohli and Devaraj (2003). MIS Quarterly, 39: 809-836.

Sangari, M. S., \& Razmi, J. (2015). Business intelligence competence, agile capabilities, and agile performance in supply chain. International Journal of Logistics Management, 26(2), 356-380.

Schmidt, J., \& Keil, T. (2013). What Makes a Resource Valuable? Identifying the Drivers of FirmIdiosyncratic Resource Value. Academy of Management Review, 38: 206-228.

Schryen, G. (2013). Revisiting IS business value research: what we already know, what we still need to know, and how we can get there. European Journal of Information Systems, 22(2), 139-169.

Seddon, P. B., Constantinidis, D., Tamm, T., \& Dod, H. (2017). How does business analytics contribute to business value? Information Systems Journal, 27(3), 237-269.

Shen, J., Li, Y., Akula, V., Yan, G., Tao, R., \& others. (2015). Gaining competitive intelligence from social media data. Industrial Management \& Data Systems, 115(9), 1622-1636.

Torres, R., Sidorova, A., \& Jones, M. C. (2018). Enabling firm performance through business 
intelligence and analytics: A dynamic capabilities perspective. Information \& Management.

Vidgen, R., Shaw, S., \& Grant, D. B. (2017). Management challenges in creating value from business analytics. European Journal of Operational Research, 261(2), 626-639.

Wade, M., \& Hulland, J. (2004). Resource-Based View and Information Systems Research: Review, Extension, and Suggestions for Future Research. MIS Quarterly, 28(1), 107-142.

Wang, Y., \& Byrd, T. A. (2017). Business analytics-enabled decision-making effectiveness through knowledge absorptive capacity in health care. Journal of Knowledge Management, 21(3), $517-539$.

Watson, H. J. (2009). Tutorial: Business Intelligence: Past, Present and Future. Communications of the Association for Information systems, 25, article 39.
Winter, S. G. (2003). Understanding Dynamic Capabilities. Strategic Management Journal, 24: 991-995.

Wixom, B. H., Yen, B., \& Relich, M. (2013). Maximizing Value from Business Analytics. MIS Quarterly Executive, 12(2): 111-123.

Wixom, B., \& Watson, H. J. (2010). The BI-based Organization. International Journal of Business Intelligence Research, 1: 13-28.

Yeoh, W., \& Popovič, A. (2016). Extending the understanding of critical success factors for implementing business intelligence systems. Journal of the Association for Information Science and Technology, 67: 134-147.

Yin, R. K. (2013). Case Study Research: Design and Methods. 5th ed. Sage Publications. 